\title{
Otolaryngology Research and Reviews
}

\section{Mini Caldwell-Luc - How We Do It}

\author{
Shaoni D Sanyal, MS, DNB ${ }^{1^{*}}$ and Ranjan Raychowdhury, MS, FRCSEd, MFSTEd $d^{1,2}$ \\ ${ }^{1}$ Department of ENT Head and Neck Surgery, Vivekananda Institute of Medical Sciences, Kolkata, \\ West Bengal, India \\ ${ }^{2}$ Consultant, Otolaryngologist/Head-Neck Surgeon, The Park Clinic, AMRI Medical Centre \& \\ Hospitals, West Bengal, India
}

\begin{abstract}
Functional endoscopic sinus surgery has become the standard of care for chronic sinus disease. However, even with angled endoscopes it is difficult to visualize the entire maxillary sinus and a failure to do so often leads to incomplete disease clearance. This article describes our variation-the Mini Caldwell Luc (MCL) procedure, which we have found effective in disease clearance with minimal morbidity. The advantage of this procedure lies in the fact that the majority or entire procedure may be performed with a 0-degree endoscope and straight instruments. The learning curve is simpler and post-operative cheek swelling and paraesthesia are minimal.
\end{abstract}

\section{Keywords}

Maxillary Sinus, Endoscopic, Paraesthesia

\section{Background}

In the 1890's, although the anatomy of the paranasal sinuses was studied in detail, the physiology was not understood well. Chronic infections of the maxillary sinuses were treated by simple drainage procedures such as trephination of the canine fossa without any counter drainage into the nose. The Caldwell-Luc procedure was described independently by two surgeons, George Caldwell of United States and Henri Luc of France in the year 1893 and 1897 respectively [1].

Functional endoscopic sinus surgery has become the standard of care for chronic sinus disease. However, even with angled endoscopes it is difficult to visualize the entire maxillary sinus and a failure to do so often leads to incomplete disease clearance [2]. In such situations, various modified Caldwell Luc approaches have been deemed useful in conjunction with transnasal endoscopic approaches. This article describes our variation - the Mini Caldwell Luc (MCL) procedure, which we have found effective in disease clearance with minimal morbidity.

\section{Technique}

The MCL is performed under general anaesthesia. Patients are supine with the head end of the operating table elevated 20-30 degrees (Reverse Trendelenberg). The nasal cavity is decongested using neuro patties soaked in $1 \mathrm{ml}$ adrenaline (1:1000) diluted in $5 \mathrm{ml}$ normal saline. With limited pathology the nasal cavity is first addressed. An uncinectomy combined with a middle meatalantrostomy is performed to allow visualisation of the sinus except where a large natural ostium already exists as in some cases of antro-choanal polyp.
The ipsilateral upper gingivolabial sulcus is infiltrated with $2 \%$ lignocaine with 1:100000 adrenaline, and a $1 \mathrm{~cm}$ horizontal stab incision is made over the canine fossa (Figure 1).

A Howarth's elevator is used to expose the canine fossa and a controlled $8 \mathrm{~mm}$ by $8 \mathrm{~mm}$ antrostomy is fashioned by osteotome or drill and rongeur (Figure 2). This bone window is large enough to allow use of a 0 degree, $4 \mathrm{~mm}$ endoscope and an instrument simultaneously. The pathology is then cleared from the maxillary sinus. An antibiotic soaked ribbon gauze pack is inserted and brought out through the nostril.

The advantage of this procedure lies in the fact that the majority or entire procedure may be performed with a 0-degree endoscope and straight instruments. The learning curve is simpler and post-operative cheek swelling and paraesthesia are minimal.

\section{Acknowledgment}

The Secretary, Ramakrishna Mission Seva Pratishthan.

*Corresponding author: Shaoni D Sanyal, Department of ENT Head and Neck Surgery, Vivekananda Institute of Medical Sciences, Ramakrishna Mission Seva Pratishthan, 99 Sarat Bose Road Kolkata 700026, West Bengal, India, Phone: +919051040747

Accepted: February 06, 2021

Published online: February 08, 2021

Citation: Sanyal SD, Raychowdhury R (2021) Mini Caldwell-Luc How We Do It. Otolaryngol Res Rev 4(1):64-65 


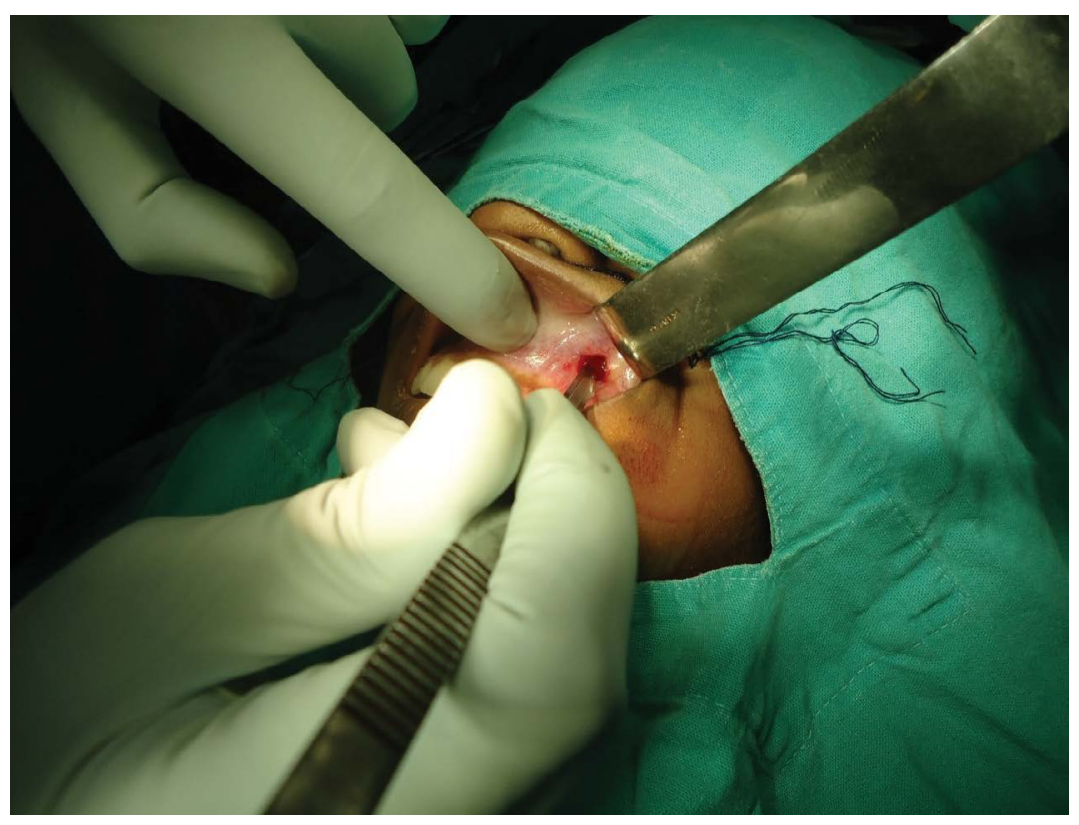

Figure 1: Stab incision over canine fossa.

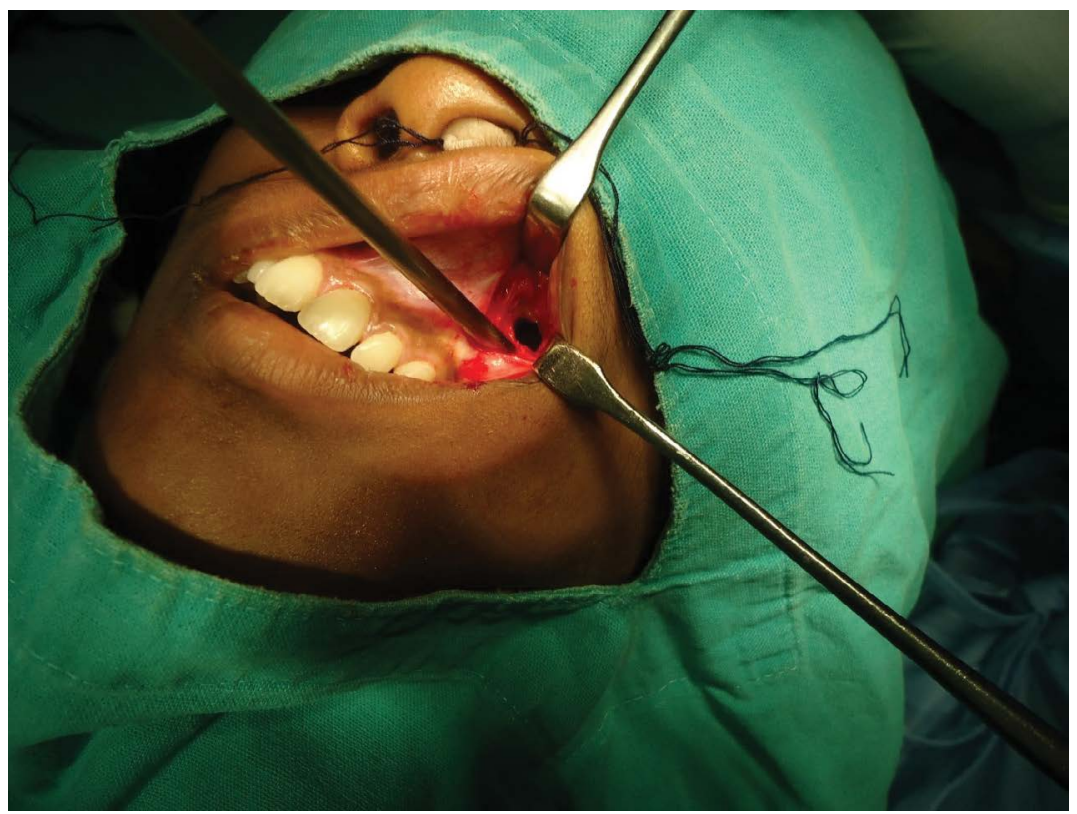

Figure 2: Controlled antrostomy $(8 \mathrm{~mm} \times 8 \mathrm{~mm})$.

\section{Financial Aid}

None.

\section{Conflict of Interest}

None.

\section{References}

1. Macbeth R (1971) Caldwell, Luc, and their operation. The Laryngoscope 81: 1652-1657.

2. Seiberling K, Ooi E, MiinYip J, et al. (2009) Canine fossa trephine for the severely diseased maxillary sinus. American J Rhinol \& Allergy 23: 615-618.

DOI: $10.36959 / 926 / 554$ 